\title{
Radio Frequency Ablation of Liver Tumor -Influence of Large Vessels location and vein wall
}

\author{
${ }^{1}$ Md.Mohaiminul Islam, ${ }^{2}$ Muhammad Asadul Islam \\ ${ }^{1,2}$ Bangladesh University of Engineering and Technology, Bangladesh; \\ ${ }^{1}$ mishkat1096@gmail.com; 2asadbuet2041@yahoo.com
}

\begin{abstract}
Radiofrequency ablation (RFA) is a process that uses RF energy which is one form of electromagnetic energy to destroy cancer cells. This is a minimally invasive technique to treat some kinds of cancer and can be applied to nonsurgical patients. The frequency range of RF current is between $300 \mathrm{kHz}$ to $1 \mathrm{MHz}$. Tumors from lung, liver, kidney and bone may be removed by performing RFA. Here in our model a patient specific simulator for Radiofrequency ablation (RFA) of liver tumors has been developed and the effects of the presence of blood vessel inside the liver tissue on the temperature distribution and the volume of ablation has been shown. And the effect of temperature distribution on the distance between large blood vessel and electrode tip has been shown, all these effects has been shown for two different models one is with vein wall and one without vein wall. Heat is generated within liver tumors utilizing RF energy from RF current where the RF current is generated using a power generator. With the heat generation, the tissue temperature reaches a temperature where cell death occurs. This cell death occurs when the cells are heated to approximately $50^{\circ} \mathrm{C}$ or above. Temperature should not exceed $100^{\circ} \mathrm{C}$ because it will cause overheating. We develop the model using ANSYS 16.2 and numerically solve the problem to view the variation of temperature around the electrode tip within the liver tissue. We consider a model with blood flow inside a vessel and which is in the vicinity of the heated tissue and a model without a vessel.
\end{abstract}

Keywords: RFA, vein, blood vessel,electrode .

\section{Introduction}

Liver cancer, also known as hepatic cancer and primary hepatic cancer, is cancer that starts in the liver [1] . Cancer which has spread from elsewhere to the liver, known as liver metastasis, is more common than that which starts in the liver [2]. Primary liver cancer is globally the sixth most frequent cancer (6\%) and the second leading cause of death from cancer (9\%) [3][2]. In 2012 it occurred in 782,000 people and resulted in 746,000 deaths [3]. There are many possible treatments for liver cancer which include surgical resection, liver transplantation, microwaves, lasers, cryotherapy and finally RFA. Surgical resection has an increased risk of complications such as liver failure and also depends on some factors such as tumor size, multifocal diseases and position of the tumor. In cryosurgery liquid Nitrogen is used to freeze the tumor tissue and thus destroys the tumor tissue. Liver transplantation requires a donor having a blood type that matches or is compatible with the recipient's. Microwave ablation is also a promising technique but 
Md. Mohaiminul Islam, Muhammad Asadul Islam; Radio Frequency Ablation of Liver Tumor-Influence of Large Vessels location and vein wall. Journal of Biomedical Engineering and Medical Imaging, Volume 4, No 6, Dec (2017), pp 16-34

currently RF is the most dominant treatment model as microwaves for ablation have to make an approach with commercial and academic developments with less invasive and easier to use technique.

\section{Background}

RFA is a widely accepted method for treating liver cancer tumors, as it offers a less invasive alternative compared to traditional surgical resection and is the method of choice for a large number of patients. Surgical resection involves a major surgical operation that isn't suitable for all patients due to multifocal disease, tumor size and location of tumor in relation to key vessels [4]. RFA can be used for a greater number of patients and it has a greater potential in repeated treatment of tumor recurrences or new metastases compared to traditional surgical resection [5]. Although RFA is commonly used for many patients, surgical resection still is the method with highest long-term survival rates [6]. This fact might partially be a result of the high recurrence rates related to RFA which is a result of surviving tumor cells close to large vessels due to the heat sink effect [7]. The liver is an organ with very high blood perfusion; blood is supplied from two large vessels, the hepatic artery and the portal vein. Large veins branching from the portal vein can be found throughout the whole liver. Numerous both experimental and numerical modelling and simulation studies have been performed to investigate the nature of RFA in liver tissue, several of these studying the effects of blood perfusion. The numerical approach is a common and popular method of studying RFA. It is both fast and inexpensive compared to experimental studies; this makes it a powerful tool both for investigating difficulties related to RFA and for the tryouts of new approaches for improving the method total occlusion. Kolios et al. showed by a numerical simulation study that microvascular perfusion of tissue plays a significant role in altering the amount of heat transferred to large vessels, where an increased perfusion decreases the cooling effect from large vessels [8]. Different approaches of decreasing blood perfusion in order to decrease the heat sink effect have been investigated; vascular occlusion due to clamping and pharmacological decrease of blood flow has both been shown to give an increase in ablation volume. According to Gilliam's will a decreasing blood flow decrease the cooling effects of perfusion but also increase the risk of vessel injuries due to ablation [9].

\section{Equipment and Methods}

\subsection{Power Generator}

The radiofrequency generator supplies RF current at a frequency at about $500 \mathrm{kHz}$ and this RF current is then applied to the patient's target tissue. Then this current flows through the patient's target tissue and then back to a ground pad which is placed on patients back or thigh. As this current always changes its direction, the ions in the area of target tissue try to follow the changes in direction of the current. Therefore, for their movement a joule heating effect is obtained around the electrode. Power output for different power generators lies between $60 \mathrm{~W}$ and $250 \mathrm{~W}$. 


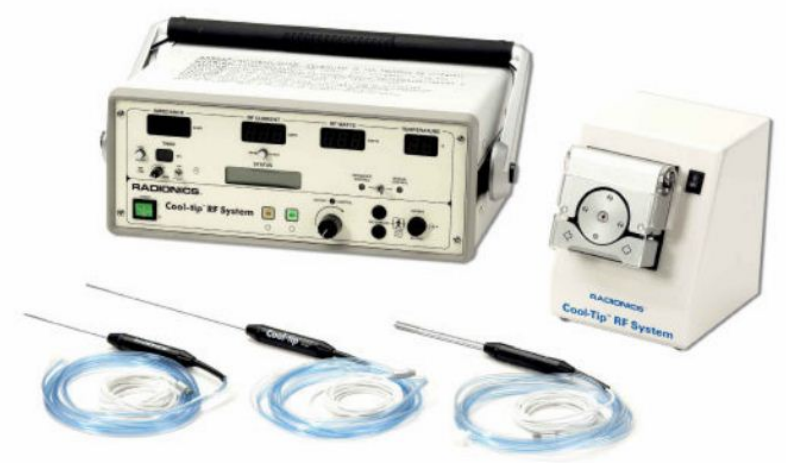

Figure 1 RF generator (upper left), cooling fluid pump (right) and three cool-tip single straight electrodes [10]

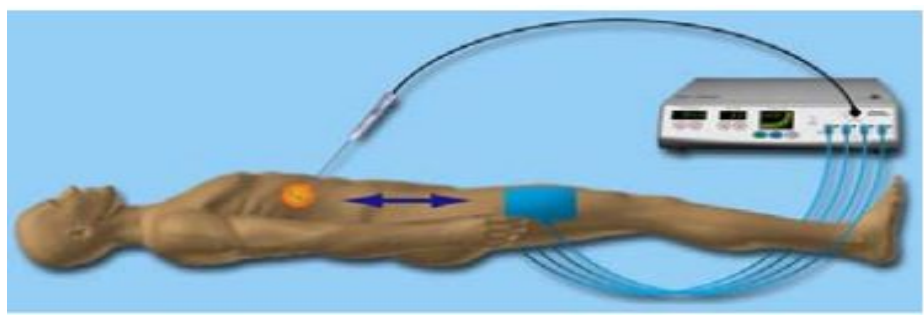

Figure 2 Application of RFA process

\subsection{Electrode}

Different types of electrode can be used in RFA.

1. Plain electrode

2. Cooled electrode

3. Wet electrode

4. Expandable electrodes

I. Multitined electrodes

II. Coiled electrodes

5. Bipolar Electrodes 


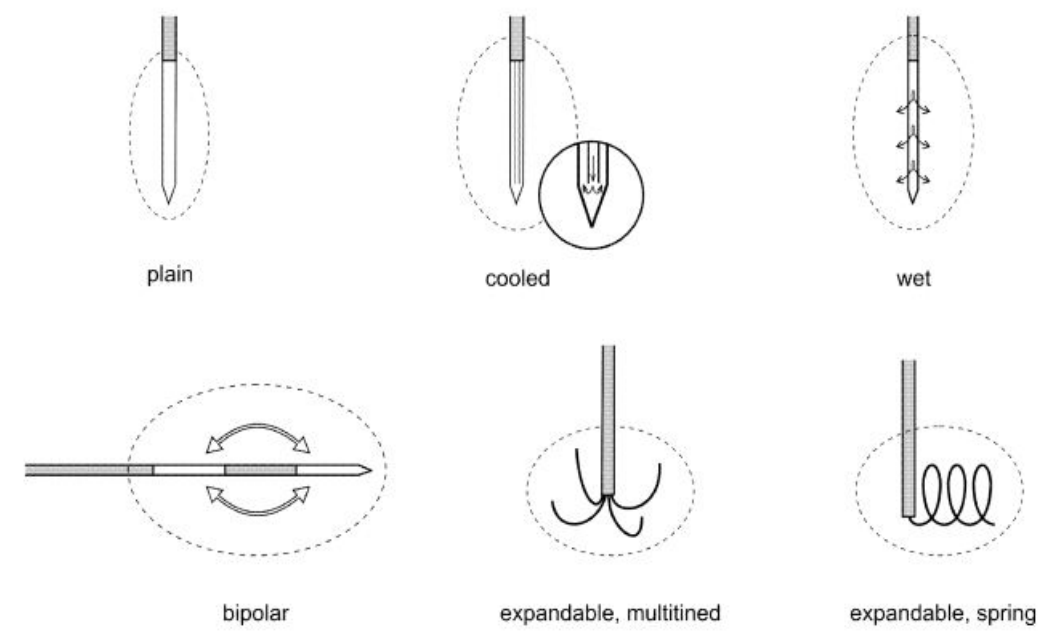

Figure 3 Different types of electrodes used in RFA

In this work, we consider a cooled electrode which has cool tip. The RF generator is supplying RF current to the cool-tip electrode which has a needle like internally cooled geometry. An external pump is used to pump cooling fluid. Cooling is done to ensure the deployment of more power into the whole tissue compared to a non-cooled electrode and thus cooling protect the tissue near the electrode from charring. Electrolyte solution can be injected into the tissue to improve thermal conductivity. But this is difficult to model.

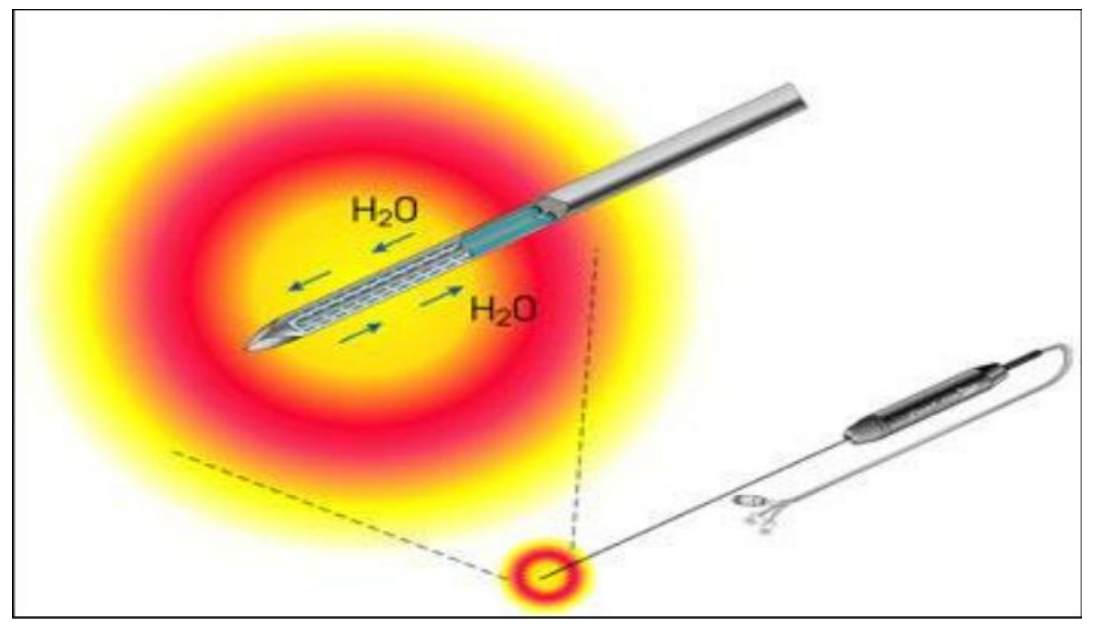

Figure 4 the Cool tip RF system [11]

Tissues can hold their stability functions upto about $40{ }^{\circ} \mathrm{C}$ but thermal injury can be occurred at any temperature above $43^{\circ} \mathrm{C}$. Irreversible cell damage will occur in a few seconds if temperature is kept higher than $50^{\circ}-{ }^{\circ} 55 \mathrm{C}$ for around 5 minutes. Instantaneous cell death will occur if temperature is kept between $60{ }^{\circ} \mathrm{C}$ and $100{ }^{\circ} \mathrm{C}$. Temperature should be kept within $100{ }^{\circ} \mathrm{C}$ because overheating occurs above this temperature which vaporizes and carbonizes the tissues that produces an insulated layer on the electrode surface and the volume of the tissue which can be treated is largely compromised [12]. The frequency of RF Current is kept around $500 \mathrm{kHz}$ and the voltage is $80 \mathrm{~V}$. 


\section{Principles of Heat Transfer and RF Tissue Heating}

Here heat transfer takes place by two mechanisms: conduction and convection. Radiation can be ignored [13].

\subsection{Conduction}

Fourier's law of conduction is

$$
q=-k \frac{\partial T}{\partial x}
$$

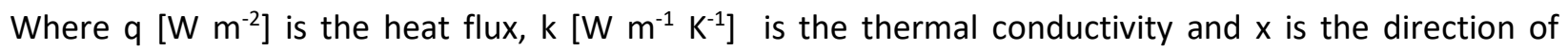
temperature gradient.

Fourier's law together with the first law of Thermodynamics gives the general heat conduction equation. The following equation will help us to know the spatial and time dependent changes of the temperature field in a heat transferring medium.

$$
\rho C \frac{\partial T}{\partial t}+\nabla \cdot(-k \nabla T)=Q
$$

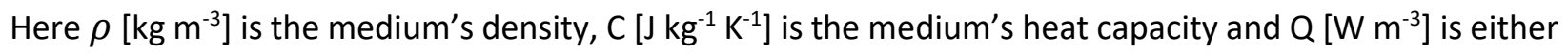
a heat source or sink.

\subsection{Convection}

Here a convective term is added to the general heat conduction equation to represent the convective heat transfer within the flowing medium.

$$
\rho C \frac{\partial T}{\partial t}+\nabla \cdot(-k \nabla T+\rho C \mathbf{u} T)=Q
$$

Here $\mathbf{u}\left[\mathrm{m} \mathrm{s}^{-1}\right]$ is the velocity field vector of the flowing fluid.

Again Newton's law of cooling represents the convective heat transfer from a medium to a fluid.

$$
q_{s}=h\left(T_{s}-T_{\infty}\right)
$$

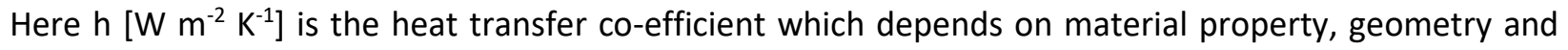
motion of the fluid flow and on fluid properties.

\subsection{Bio-heat transfer}

Heat transfer in tissue is also affected by the blood perfusion. Convection occurs between solid tissue and flowing blood for blood vessel of all sizes. Vessel size, flow velocities and number of vessels in the volume of interest have impact on the convection between tissue and blood. Pennes Bio-heat equation adds blood perfusion and generated metabolic heat terms in general heat conduction equation.

$$
\rho C \frac{\partial T}{\partial t}=\nabla \cdot(k \nabla T)-m_{b} C_{b}\left(T-T_{b}\right)+Q_{m}
$$

Where $m_{b}, C_{b}$ and $T_{b}$ is mass flow rate, specific heat and temperature of the blood respectively [14]. $Q_{m}$ is the heat generated in the metabolic process and this is negligible [15]. It is assumed in the Pennes Bio- 
Md. Mohaiminul Islam, Muhammad Asadul Islam; Radio Frequency Ablation of Liver Tumor-Influence of Large Vessels location and vein wall. Journal of Biomedical Engineering and Medical Imaging, Volume 4, No 6, Dec (2017), pp 16-34

heat equation that all the heat transfer between tissue and blood occurs in the capillary bed that means capillary blood flow act as a heat sink [16].

\subsection{RF tissue heating}

RF tissue heating is based on the principle of inducing an ion current into tissue by the application of a RF field between an electrode and a grounding pad. The friction that ion movement in the tissue causes results in so-called joule heating (resistive heating). Biological tissues can be treated as quasi-static in the $\mathrm{RF}$ range $(300 \mathrm{kHz}-1 \mathrm{Mhz})$, this means that they can be described as purely resistive, neglecting the small part of impedance that dielectric permittivity constitutes. Electric field, $\mathrm{E}$ [V $\mathrm{m}-1]$, applied to a tissue can be described by Laplace's equation:

$$
-\nabla(\sigma \nabla E)=-\nabla \sigma E=0
$$

Where $\sigma(\mathrm{S} / \mathrm{m})$ is the electrical conductivity, $\mathrm{V}(\mathrm{V})$ is the potential and $\nabla$ the gradient Operator. The electrical conductivity $\sigma$ is the ability of a material to carry the flow of an electric current and depends on concentration of the ions, temperature of the solution, specific nature of the ions. Conductivity value also depends on time and temperature.

Although the exact behavior of $\sigma$ dependency of temperature in tissues in unknown, for temperature ranges around body temperature the electrical conductivity increases linearly; when $100 \circ \mathrm{C}$ are achieved in the tissue, boiling and vaporization will occur, and thus raise of tissue impedance and insulating effects of gas bubbles, leading to an electrical conductivity decrease .

Moreover, the determination of the electrical conductivity is a rapid and convenient means of estimating the concentration of ions in solution [17].

The Ohm's law demonstrates the relation between current flux J, the intensity of the electric field $\mathrm{E}$ and the electrical conductivity:

$$
\mathrm{J}=\sigma \mathrm{E}
$$

where $\mathrm{J}$ is the current density $\left(\mathrm{A} / \mathrm{m}^{2}\right)$ and $\mathrm{E}$ is the electric field intensity $(\mathrm{V} / \mathrm{m})$.

The product of current density $\mathrm{J}$ and electric field intensity $E$ generates the power density.

\subsection{Fluid flow type}

Fluid flow are of two types: turbulent and laminar. When the fluctuations of velocity are random it is turbulent flow and the fluctuations of velocity don't occur, it is laminar flow [18]. The Reynolds number is an important parameter to determine whether a flow is laminar or turbulent. When Reynolds number is less than 2300, the flow is laminar and any value greater than 4000 is turbulent. This are valid for flow in pipes. Reynolds number for a pipe can be expressed by the following equation

$$
R e=\frac{\bar{u} D}{v}
$$

Here $D$ is the diameter of the pipe, $\bar{u}$ is the mean velocity and $v$ is the kinematic viscosity.

The blood flow in human body is laminar. It can be seen from the velocity profile which is parabolic in shape with $\mathrm{v}=0$ at the vessel wall and highest at the center of the stream. So the energy losses in the flowing blood is reduced due to the orderly movement of the adjacent layer of blood flow [19]. 


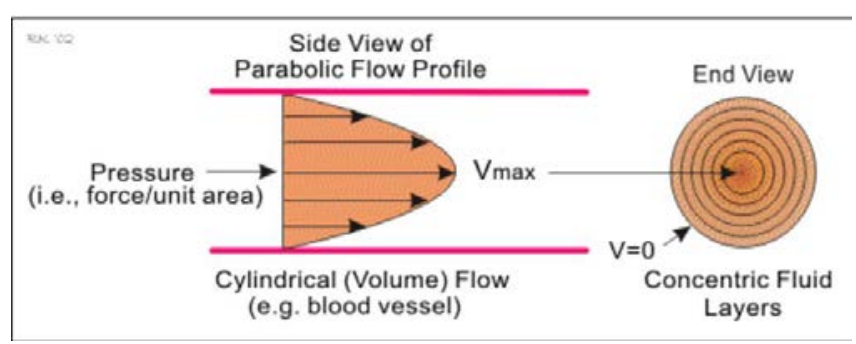

Figure 5 Parabolic flow profile[19]

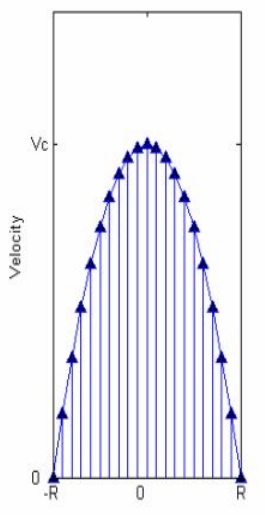

Figure 6 Fully developed laminar velocity profile

\section{$5 \quad$ RFA modelling with ANSYS}

\subsection{Geometry and materials properties}

\subsubsection{Liver}

The liver tissue is assumed cylindrical in shape. The diameter of the cylinder is $50 \mathrm{~mm}$ and height is 100 $\mathrm{mm}$. Thermal conductivity of perfused liver is $2.18 \mathrm{~W} \mathrm{~m}^{-1} \mathrm{~K}^{-1}[20]$ The material properties of the liver tissue is shown in the figure below:

\begin{tabular}{lccc}
\hline Name & Symbol & Unity & Value \\
\hline Density & $\rho$ & $\mathrm{kg} / \mathrm{m}^{3}$ & 1,060 \\
Specific heat & $\mathrm{C}$ & $\mathrm{J} / \mathrm{kg} \cdot \mathrm{K}$ & 3,600 \\
Heat conductivity & $\mathrm{k}$ & $\mathrm{W} / \mathrm{m} \cdot \mathrm{K}$ & 0.512 \\
Resistivity & $\sigma$ & $\Omega \cdot \mathrm{m}$ & 3.003 \\
\hline
\end{tabular}

Figure 7 Thermal and electrical properties of liver [21]

\subsubsection{Blood and vein}

The vein is hollow cylindrical with a diameter of $4 \mathrm{~mm}$ and the thickness of the vein is $0.5 \mathrm{~mm}$. The blood flows inside the vein. The property for blood and vein is given in the figure below:

\begin{tabular}{lcc}
\hline Property & Symbol & Value \\
\hline Density of blood & $\rho_{b}$ & $1050 \mathrm{~kg} / \mathrm{m}^{3}$ \\
Dynamic viscosity of blood & $\mu_{b}$ & $0.0035 \mathrm{~kg} / \mathrm{m} \cdot \mathrm{s}$ \\
Density of vein wall & $\rho_{w}$ & $1120 \mathrm{~kg} / \mathrm{m}^{3}$ \\
Specific heat of blood & $C_{p b}$ & $3820 \mathrm{~J} / \mathrm{kg}{ }^{\circ} \mathrm{C}$ \\
Specific heat of vein wall & $C_{p w}$ & $3780 \mathrm{~J} / \mathrm{kg}^{\circ} \mathrm{C}$ \\
Thermal conductivity of blood & $K_{b}$ & $0.492 \mathrm{~W} / \mathrm{m} \cdot \mathrm{K}$ \\
Thermal conductivity of vein wall & $K_{w}$ & $0.56 \mathrm{~W} / \mathrm{m} \cdot \mathrm{K}$ \\
& &
\end{tabular}

Figure 8 Material property of blood and vein [22]. 
Md. Mohaiminul Islam, Muhammad Asadul Islam; Radio Frequency Ablation of Liver Tumor-Influence of Large Vessels location and vein wall. Journal of Biomedical Engineering and Medical Imaging, Volume 4, No 6, Dec (2017), pp 16-34

\subsubsection{Electrode}

The electrode has two parts, electrode base and electrode tip. The electrode base is made of plastic. The electrode has a height of $90 \mathrm{~mm}$. and diameter of $2 \mathrm{~mm}$.

\begin{tabular}{|c|c|}
\hline Constant & Value \\
\hline $\begin{array}{l}\text { Electrode electrical } \\
\text { conductivity }\end{array}$ & $7.4 \mathrm{e} 6 \mathrm{~S} / \mathrm{m}$ \\
\hline $\begin{array}{l}\text { Electrode thermal } \\
\text { conductivity }\end{array}$ & $15 \mathrm{~W} / \mathrm{m} \cdot \mathrm{K}$ \\
\hline Electrode density & $8000 \mathrm{~kg} / \mathrm{m}^{3}$ \\
\hline Electrode specific heat & $480 \mathrm{~J} / \mathrm{kg} \cdot \mathrm{K}$ \\
\hline $\begin{array}{l}\text { Plastic electrical } \\
\text { conductivity }\end{array}$ & $1 \mathrm{e}-5 \mathrm{~S} / \mathrm{m}$ \\
\hline $\begin{array}{l}\text { Plastic thermal } \\
\text { conductivity }\end{array}$ & $0.026 \mathrm{~W} / \mathrm{m} \cdot \mathrm{K}$ \\
\hline Plastic density & $70 \mathrm{~kg} / \mathrm{m}^{3}$ \\
\hline Plastic specific heat & $1045 \mathrm{~J} / \mathrm{kg} \cdot \mathrm{K}$ \\
\hline
\end{tabular}

Figure 9 Material property of electrode [23]

All the parts are sketched in Solidworks 2016 and assembled to get the final assembly.

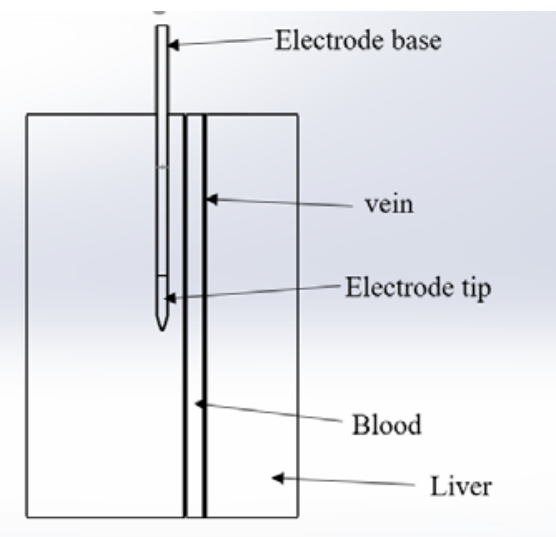

Figure 10 Schematic view of the model (with vein wall)

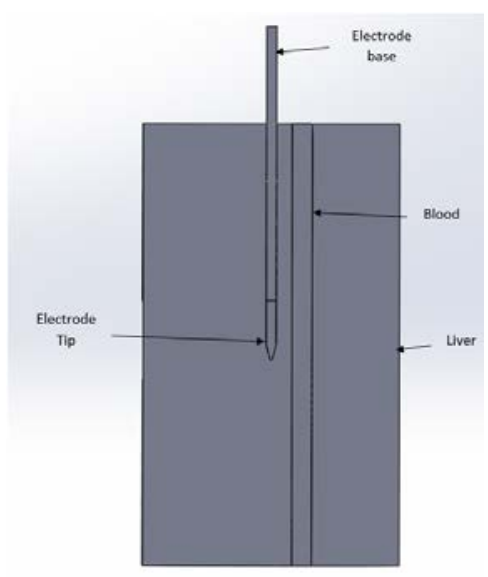

Figure 11 Schematic view of the model (without vein wall)

\subsection{Mesh}

The principal concept of FEM is to divide a region (1D, 2D or 3D), over which a certain physical behavior and differential equation is valid, into smaller elements. A region divided into elements is called mesh. The mesh element for a 1D-region constitutes of linear segments where the end points constitute the nodes of the mesh. For 2D, triangular shaped mesh elements can be used where the three corners constitute the nodal points. For 3D, tetrahedrons can be used as mesh elements where the four corner points constitute the nodes [24]. Both for 2D and 3D cases other geometries then the above mentioned can be used as mesh elements, such as rectangular- and box like geometries. The number of elements that the region of interest is divided into will partly steer the accuracy of the solution, where more mesh 
elements offers a more accurate approximation. An increase in the number of mesh elements also increases the size of the equation system that has to be solved.

The mesh size in the liver was set to increase smoothly from the middle of the model to the outer boundary so that we keep a finer mesh around the electrode and the vessel but a coarser one in the liver external walls. It is important to set a slow transition between the center of the model to the its boundaries in order to prevent numerical instabilities. Details of mesh analysis is described in appendix 1.

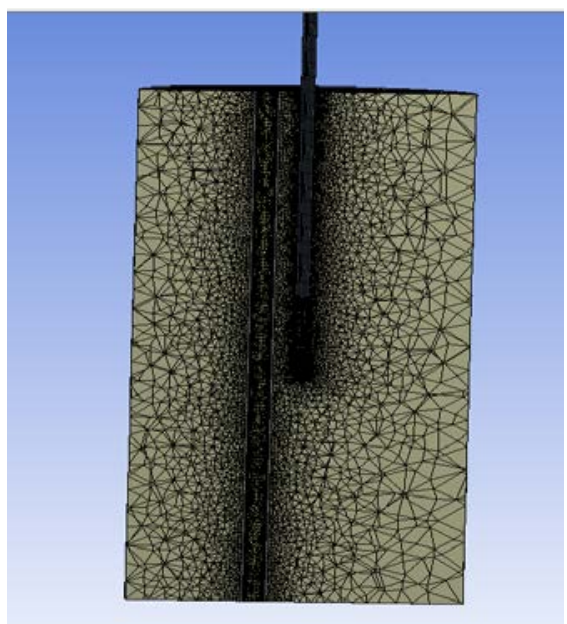

Figure 12 (a) Schematic view of the mesh distribution (sectional view)

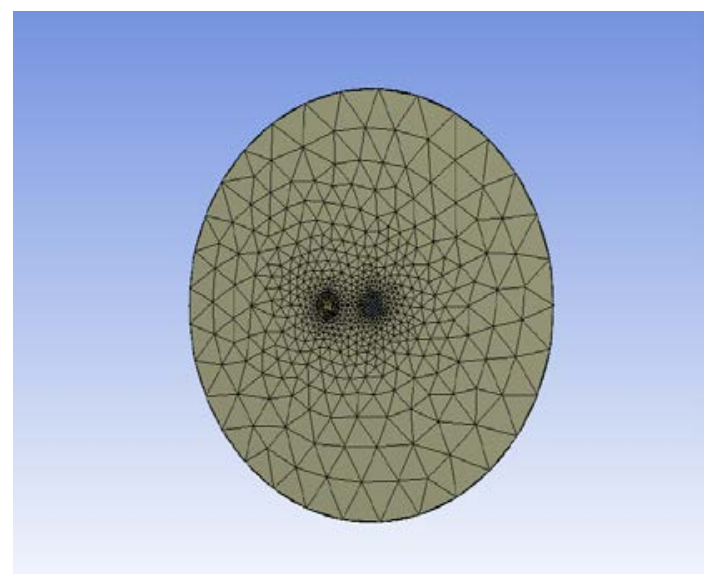

Figure 12 (b) Schematic view of the mesh distribution.(top)

\subsection{Boundary conditions (BCs)}

The geometry is divided into so called sub-domains that are regions separated by boundaries. It is very important to impose correct computational domains and boundary conditions for not affecting the accuracy of the results. Once the boundary conditions for all domains (liver and vessel) are set correctly, it is possible to launch the simulation.

The outer boundaries of the liver and the inlet of the blood vessel are modeled with a Dirichlet condition of $37^{\circ} \mathrm{C}$ equal to the body temperature.

The symmetry plane is set with the condition of zero heat flux (Newman condition) and the blood flow velocity has been randomly set at a low value of $2 \mathrm{~mm} / \mathrm{s}$.

According to the operating principle of the Cool-tip electrode and to the Dirichlet conditions, the convective cooling by fluid flow is large enough to guarantee a constant temperature on the outer surface of the electrode. Moreover, measurements done by Welp et al. in ex vivo experiments on liver tissue with a cool-tip $2 \mathrm{~mm}$ electrode, demonstrated that for the entire duration of the thermal treatment the tip electrode temperature were almost constant at $10^{\circ} \mathrm{C}$. Based on that, the assumption for the temperature electrode wall is equal to $10^{\circ} \mathrm{C}$. 
Md. Mohaiminul Islam, Muhammad Asadul Islam; Radio Frequency Ablation of Liver Tumor-Influence of Large Vessels location and vein wall. Journal of Biomedical Engineering and Medical Imaging, Volume 4, No 6, Dec (2017), pp 16-34

\begin{tabular}{|c|c|}
\hline Domain & Boundary Conditions \\
\hline vein & Initial temperature $37^{\circ} \mathrm{C}$ \\
\hline blood & Initial temperature $37^{\circ} \mathrm{C}$ and velocity $2 \mathrm{~mm} / \mathrm{s}$ \\
\hline liver & Initial temperature $37^{\circ} \mathrm{C}$ \\
\hline electrode & Temperature fixed at $10^{\circ} \mathrm{C}$ and fixed $80 \mathrm{~V}$ at \\
& electrode tip \\
\hline
\end{tabular}

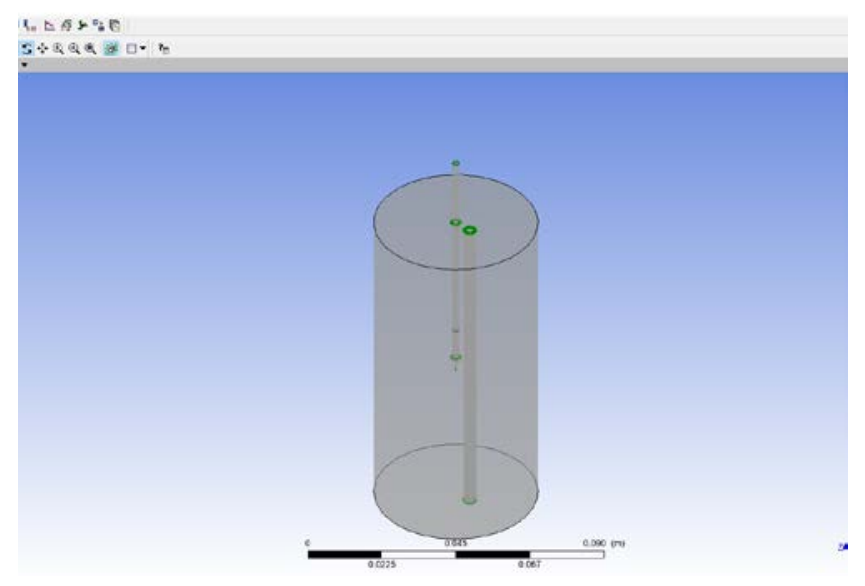

Figure 13 Shows different domains

\section{Result}

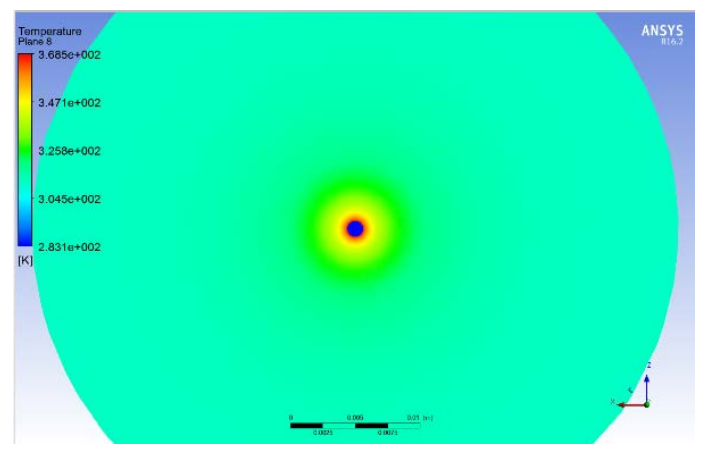

Figure 14 shows the unaffected symmetrical ablation volume which is created when no large blood vessel is present in the model

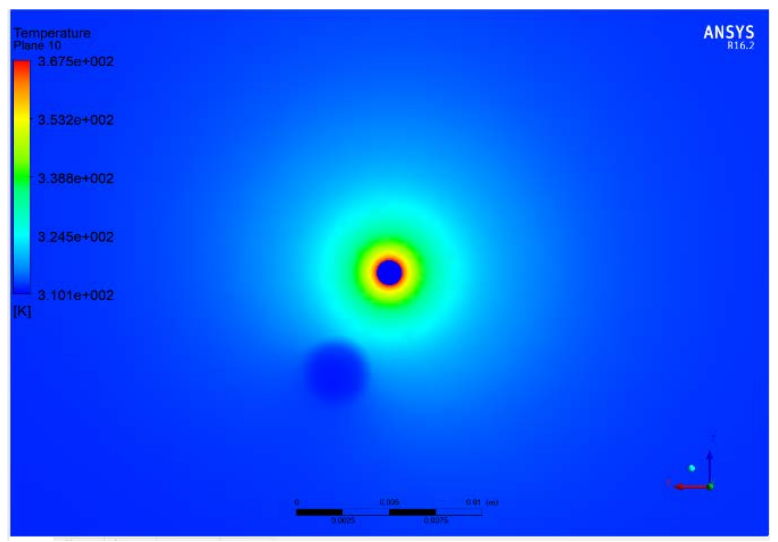

Figure 15 shows the impact of large blood vessel considering no vein wall ( $6 \mathrm{~mm}$ from electrode) 


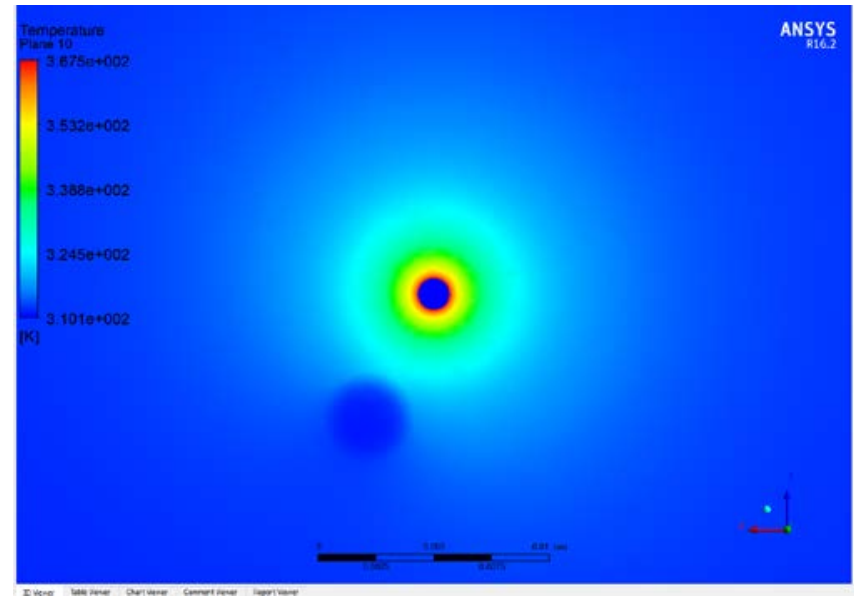

Figure 16 shows the impact of large blood vessel considering vein wall (6 $\mathrm{mm}$ from electrode)

In this model the blood vessel of $4 \mathrm{~mm}$ diameter was $6 \mathrm{~mm}$ from electrode (center to center). It can be seen that maximum temperature in the absence of blood vessel was a little higher. And ablation zone was larger in the absence of blood vessel. Both can be described by heat sink effect of large blood vessel. For $6 \mathrm{~mm}$ distance of large vessel, presence of vein wall had no effect. And temperature distribution was symmetric. For effective RFA modelling It was necessary to set an assumption - Ablative temperature less than $100^{\circ} \mathrm{C}$ to be maintained constant during the therapy;

Because temperature higher than $100^{\circ} \mathrm{C}$ causes vaporization, carbonization, charring of tissue and cause to increase impedance. Taking into account both assumptions and considering the initial temperature value (body temperature of $37^{\circ} \mathrm{C}$ ) in the model, it was possible to define an ideal curve.

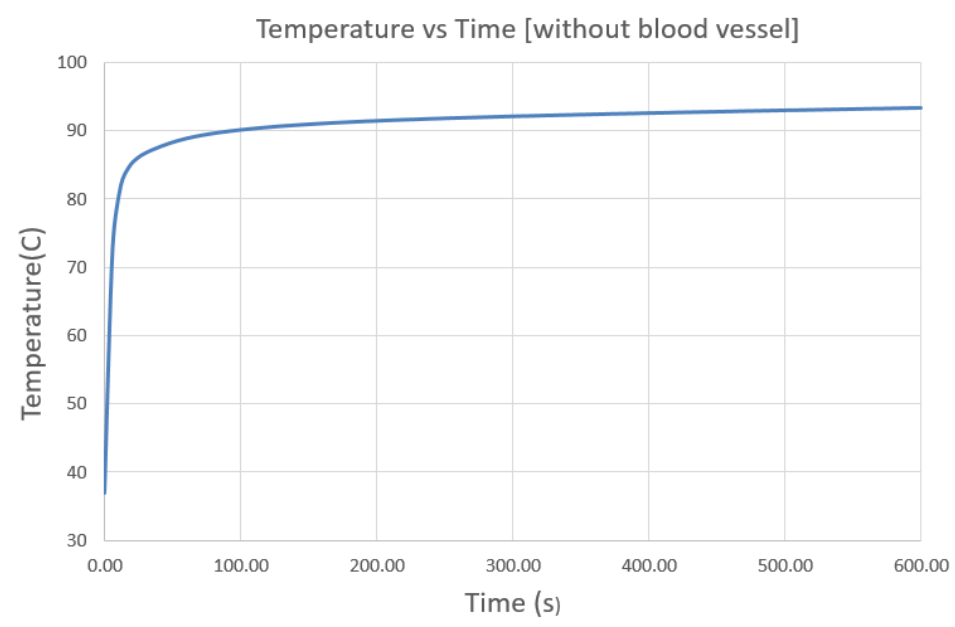

Figure 17 shows variation of temperature with time at electrode tip (doesn't contain blood vessel) 
Md. Mohaiminul Islam, Muhammad Asadul Islam; Radio Frequency Ablation of Liver Tumor-Influence of Large Vessels location and vein wall. Journal of Biomedical Engineering and Medical Imaging, Volume 4, No 6, Dec (2017), pp 16-34

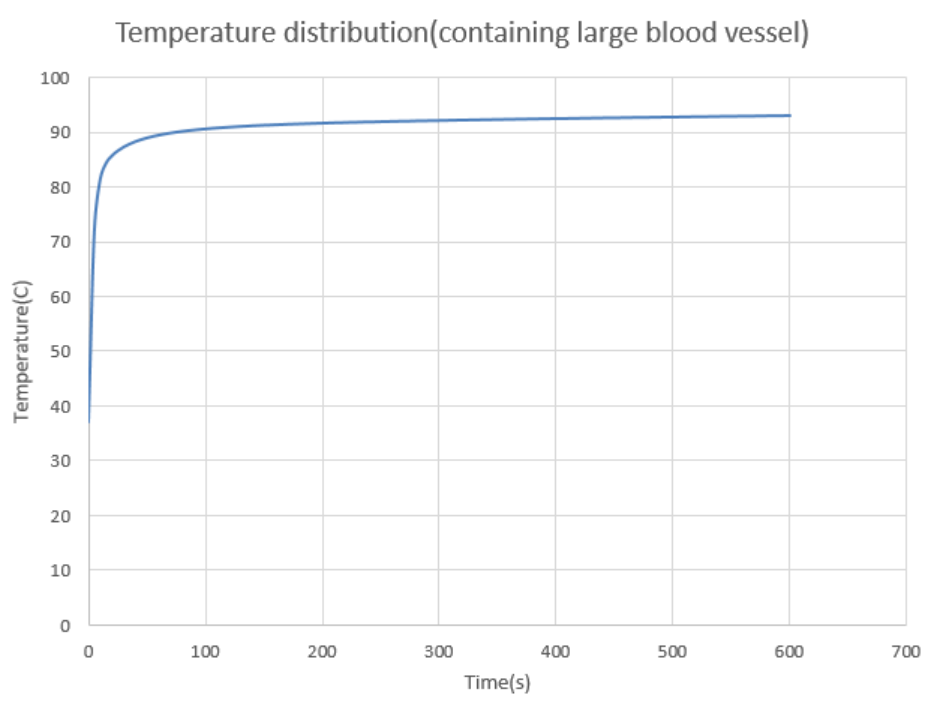

Figure 18 shows variation of temperature with time at electrode tip (containing large blood vessel $6 \mathrm{~mm}$ from electrode)

Figure 5.12 was obtained keeping blood vessel at $6 \mathrm{~mm}$ from electrode in both cases (considering vein wall and not considering vein wall) gave same temperature distribution. Temperature distribution was uniform throughout.

Similar simulation was done using COMSOL and the result is following graph.

SOURCE https://www.comsol.com/model/download/326381/models.heat.tumor ablation.pdf
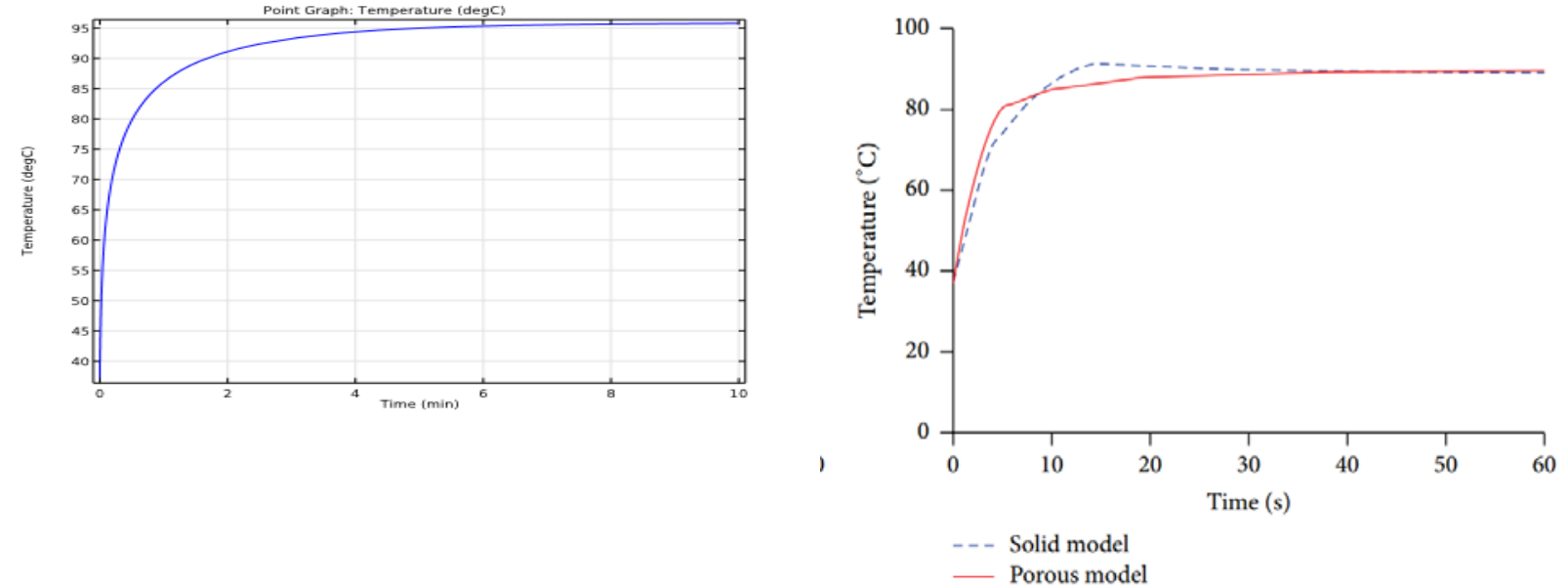

(Similar results were obtained by Montree Chaichanyut and Supan Tungjitkusolmun in 2016 [25])

To find the effect of large blood vessel location, position of the blood vessel was changed to $5 \mathrm{~mm}$ from electrode and figure 5.13 and 5.14 was obtained. 


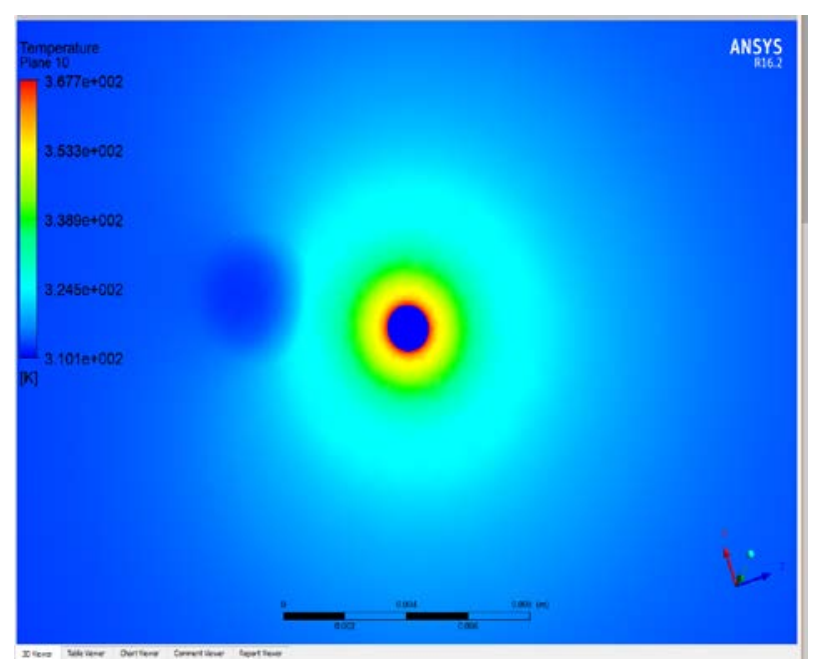

Figure 19 shows the impact of large blood vessel not considering vein wall ( $5 \mathrm{~mm}$ from electrode)

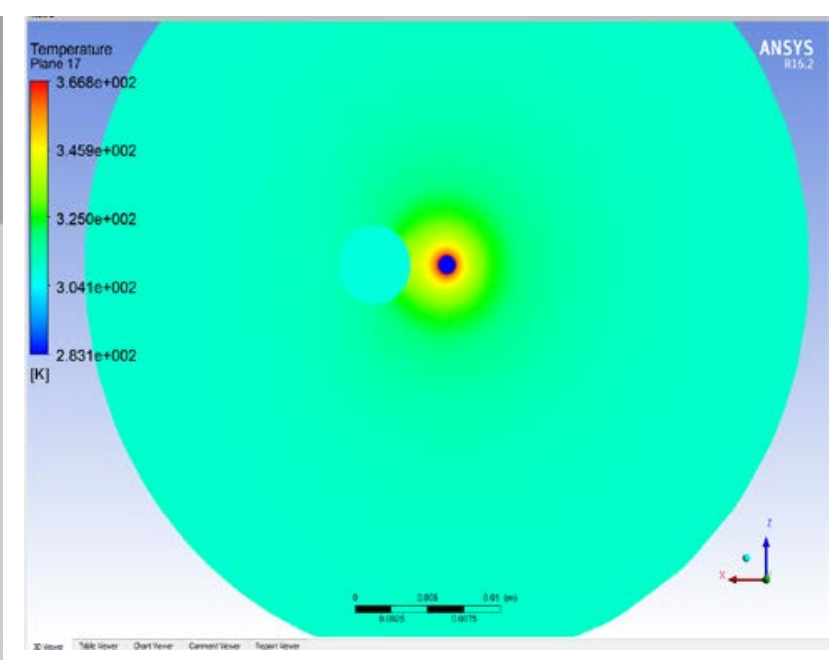

Figure 20 shows the impact of large blood vessel considering vein wall (5 $\mathrm{mm}$ from electrode)

An interesting observation in this simulation was, though temperature was lower at vessel side when we didn't consider vein wall it changed when we considered vein wall. Temperature was higher at vein wall than other side.

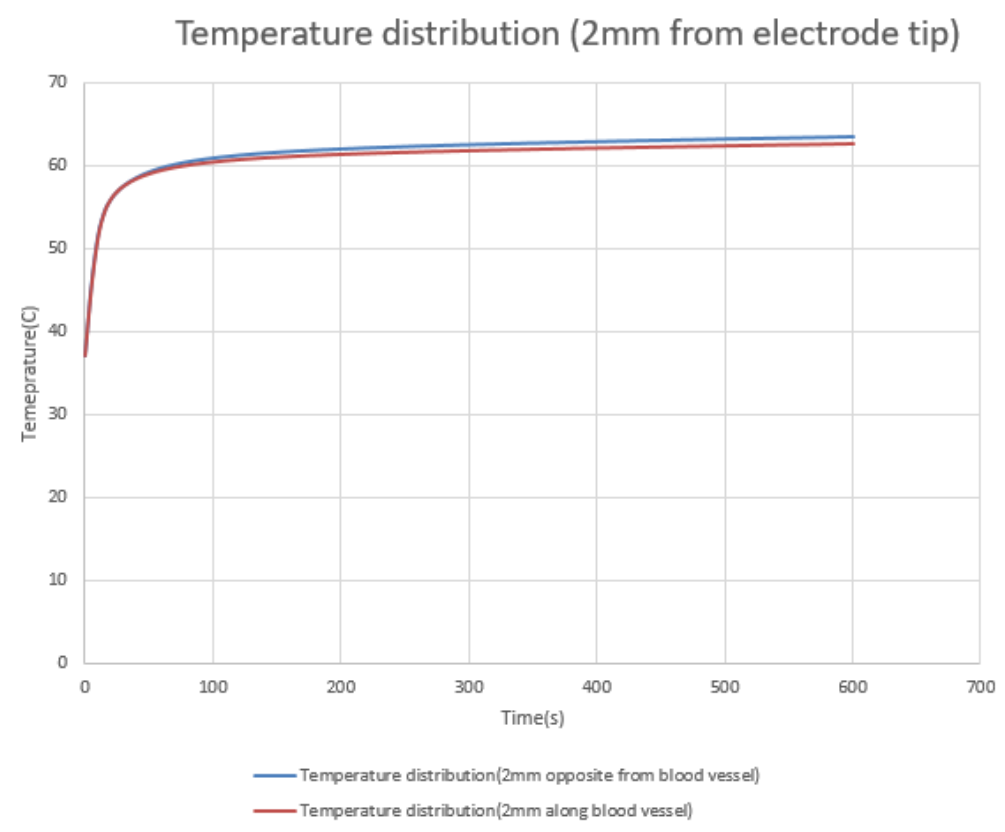

Figure 21 Shows variation of temperature between equally spaced $(2 \mathrm{~mm})$ one in blood vessel side and another on the opposite side (not considering vein wall). 
Md. Mohaiminul Islam, Muhammad Asadul Islam; Radio Frequency Ablation of Liver Tumor-Influence of Large Vessels location and vein wall. Journal of Biomedical Engineering and Medical Imaging, Volume 4, No 6, Dec (2017), pp 16-34

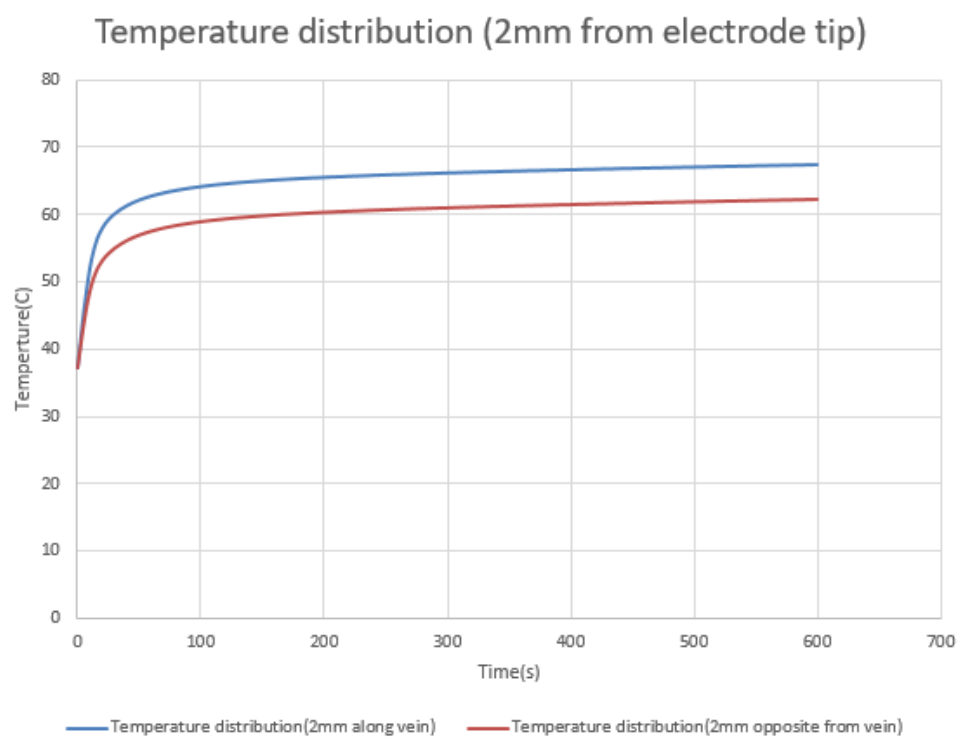

Figure 22 shows variation of temperature between equally spaced $(2 \mathrm{~mm})$ one in blood vessel side and another on the opposite side (considering vein wall).

Figure 4.15 \& Figure 4.16 shows temperature distribution $2 \mathrm{~mm}$ from electrode one considering vein wall another not considering vein wall. Again temperature was little lower at blood vessel side when vein wall was not considered, But this trend changed when vein wall was considered, In this case temperature was higher at blood vessel side.

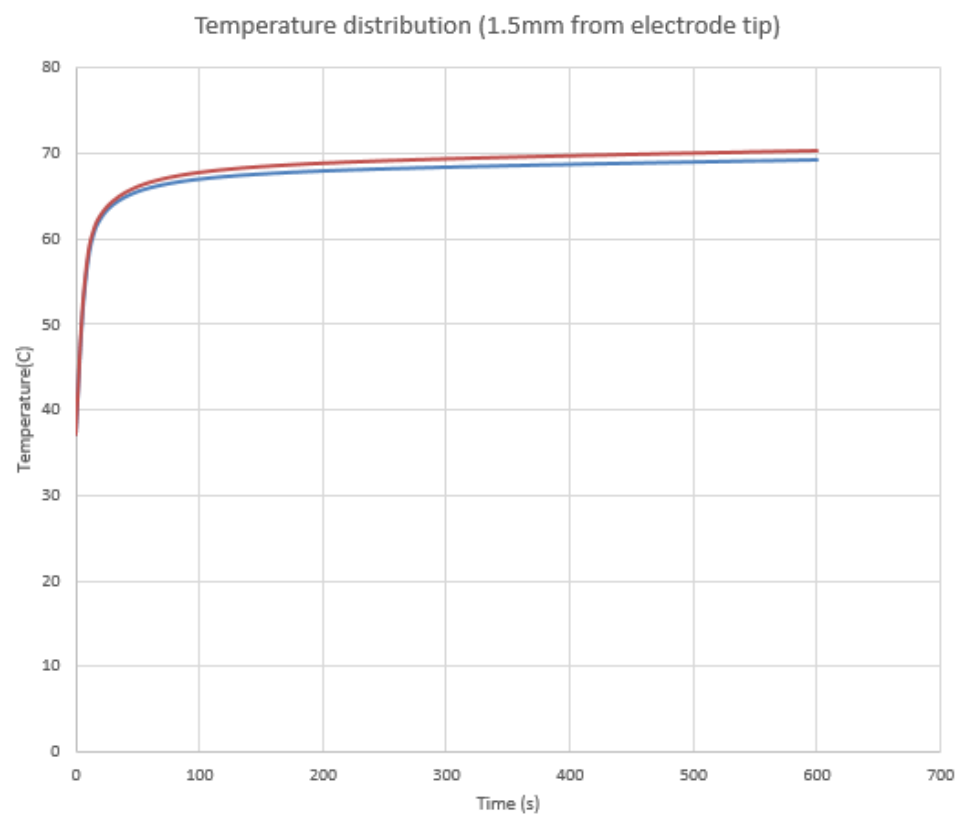

— Temperature distribution(1.5mm al ong blood vessel)"

Figure 23 shows variation of temperature between equally spaced $(1.5 \mathrm{~mm})$ one in blood vessel side and another on the opposite side(not considering vein wall). 


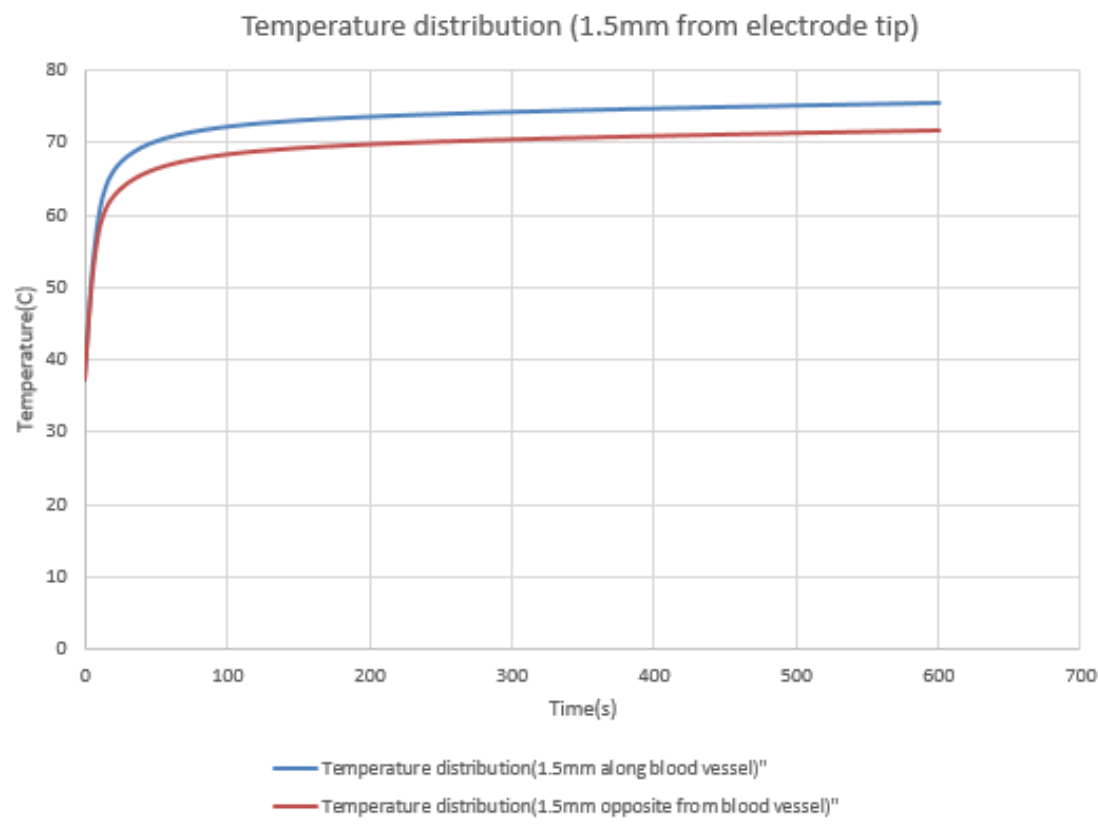

Figure 24 shows variation of temperature between equally spaced $(1.5 \mathrm{~mm})$ one in blood vessel side and another on the opposite side ( considering vein wall).

This trend continues for temperature distribution at $1.5 \mathrm{~mm}$ distance. Again temperature was higher at blood vessel side when vein wall was considered and lower vein was not considered.

Now we decreased distance of blood vessel and electrode tip to $4 \mathrm{~mm}$.

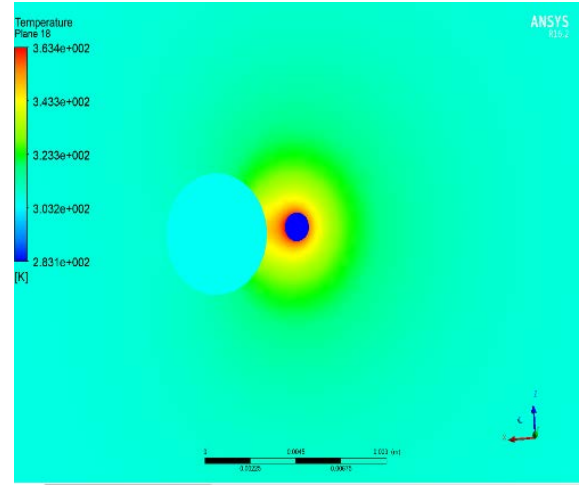

Figure 25 shows the impact of large blood vessel considering vein wall ( $4 \mathrm{~mm}$ from electrode)

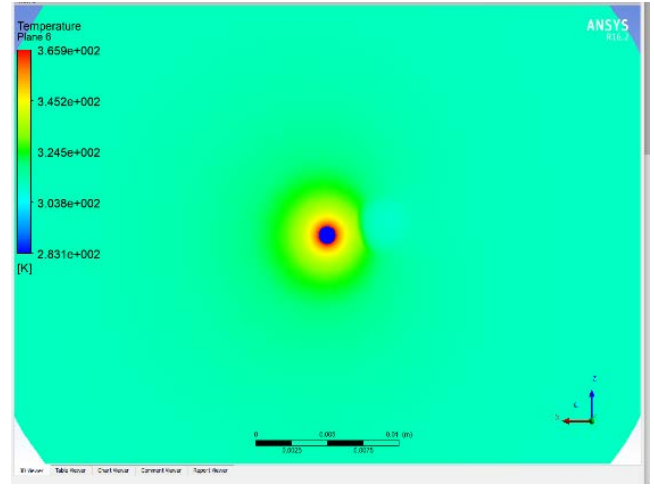

Figure 26 shows the impact of large blood vessel not considering vein wall ( $4 \mathrm{~mm}$ from electrode) 
Md. Mohaiminul Islam, Muhammad Asadul Islam; Radio Frequency Ablation of Liver Tumor-Influence of Large Vessels location and vein wall. Journal of Biomedical Engineering and Medical Imaging, Volume 4, No 6, Dec (2017), pp 16-34

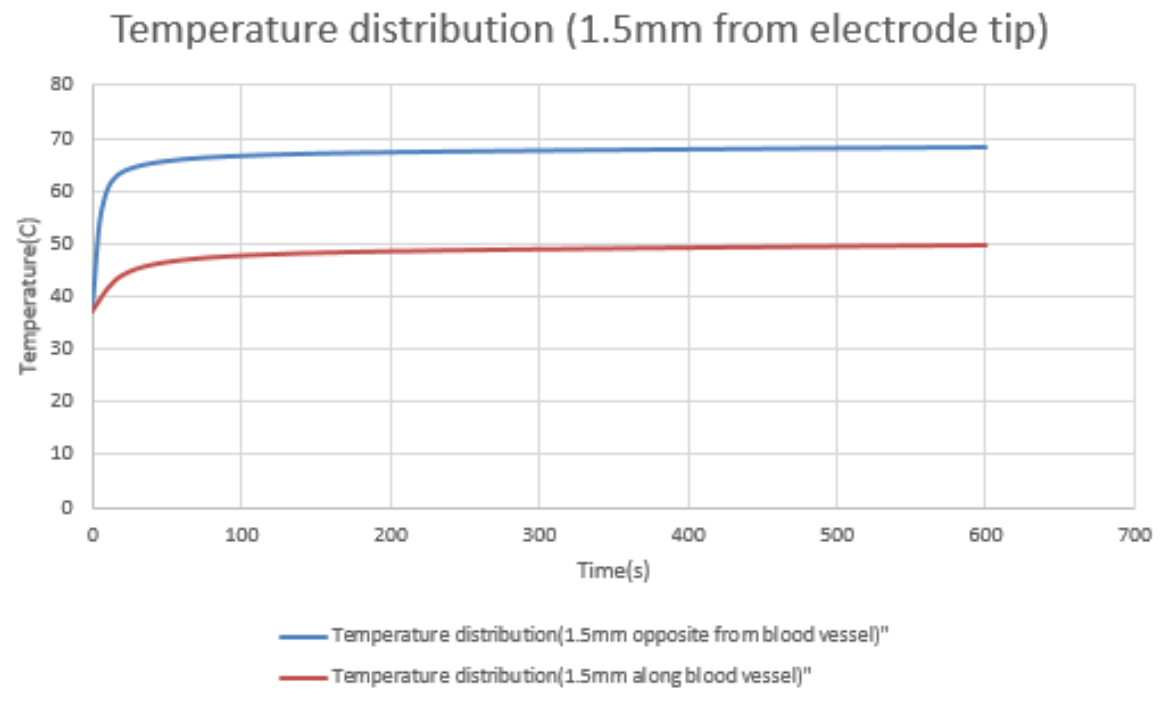

Figure 27 shows variation of temperature between equally spaced $(1.5 \mathrm{~mm})$ one in blood vessel side and another on the opposite side (not considering vein wall).

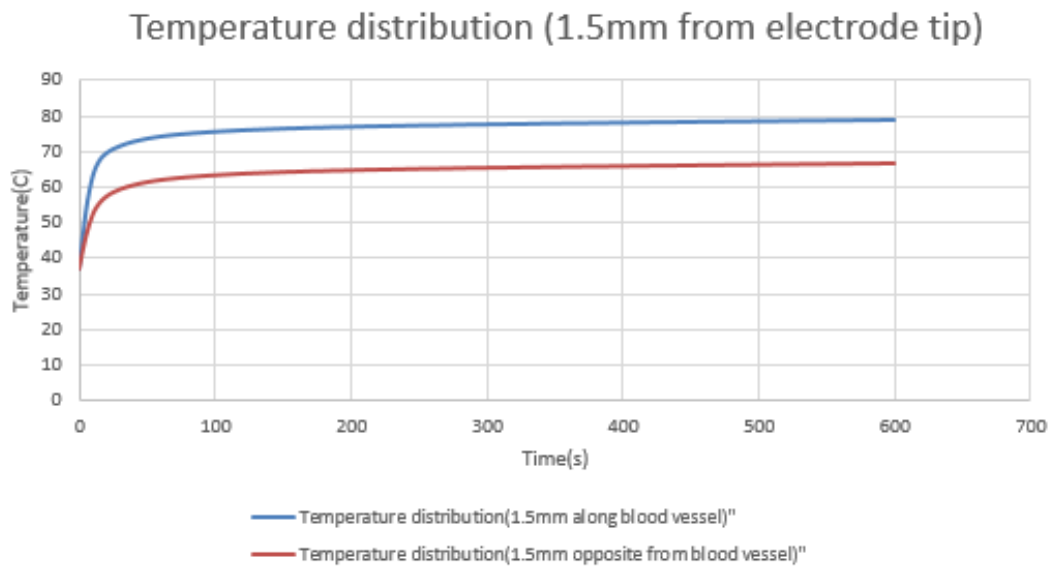

Figure 28 shows variation of temperature between equally spaced $(1.5 \mathrm{~mm})$ one in blood vessel side and another on the opposite side (considering vein wall).

And again the same thing happened. So it can be seen that as the distance between large vessel and electrode decreased effect of sink effect of blood increased. When vein wall was not considered temperature of vessel side was less than opposite side and when vein wall was considered this trend changed and temperature was higher at vessel side. Higher temperature at vessel side may cause cell damage.

\section{Discussion}

When considering the results of this work we have to be aware of the large uncertainties and approximations which are associated with modelling complex biological situations with bio heat transfer models. It has to be emphasized that the results of this report only work as a prediction of the used model; the results can't in any way be extrapolated to the real in vivo situation without performing any verifying in vivo experiments. In spite of this the work can be seen as guiding in a qualitative manner when 
considering RF heating and heat transfer in the vicinity of large vessels. Strengthening for the developed model is the attempt to bring together a tissue perfusion model with modelling of blood flow within large vessels. A shortcoming of the developed model is the lack of temperature dependent thermal conductivity. It is very likely that thermal conductivity of tissue depends on temperature, either by changes in blood perfusion or by changes in other tissue properties. It is likely to believe that thermal conductivity increases for relatively small increases in tissue temperature due to increasing tissue perfusion. In addition it is possible to believe that thermal conductivity decreases, to a value lower than that for $37^{\circ} \mathrm{C}$, for high temperatures due to coagulation of blood in the microvascular blood flow. This behavior makes it difficult to model thermal conductivity of tissues in a reliable manner. A possible effect of temperature dependent thermal conductivity on the ablation result is a lowering of the heat sink effect for high temperatures, due to decreasing thermal conductivity. At the same time it is possible to believe that a decrease in thermal conductivity results in a heating more centralized around the electrode, resulting in a smaller ablation volume. To increase the accuracy of the second degree regression model a larger number of simulations would have been necessary; this was not possible to perform due to the limited time frame of this work.

\section{Conclusions and Future Works}

From the result, it has been seen that the temperature near the vein wall is more compared to the temperature at a point in the opposite direction which might cause cell damage within the vicinity of vein wall. But if we do not consider vein wall temperature distribution becomes more uniform.

Again if we increase the distance between electrode and blood vessel, the heat sink effect will decrease and that increases the simulated model's volume of ablation. For a certain distance (for our case $6 \mathrm{~mm}$ ) there was no effect of presence of blood vessel, as the distance decreased heat sink effect of blood vessel increased .If blood flow velocity and vessel diameter increases, the heat sink effect will increase and that decreases simulated model's ablation volume, And increased blood flow may help to lower temperature at vein wall help preventing cell damage.

Since experimental verification is not done, a more accurate model can be developed in the future by comparing between the practical experiments and the simulation results. We can test our model by changing number of vessel, dimensions and parameters such as blood flow velocity, distance between electrode and vessel, angle between RF electrode and blood vessel, treatment time and applied power

\section{REFERENCES}

[1] "Adult Primary Liver Cancer Treatment (PDQ $\left.{ }^{\circledR}\right)-$ Patient Version". NCl. 6 July 2016. Retrieved 29 September 2016.

[2] World Cancer Report 2014. World Health Organization. 2014. pp. Chapter 5.6. ISBN 9283204298.

[3] GBD 2013 Mortality and Causes of Death, Collaborators (17 December 2014). "Global, regional, and national age-sex specific all-cause and cause-specific mortality for 240 causes of death, 1990-2013: a systematic analysis for the Global Burden of Disease Study 2013.". Lancet. 385: 117-71. doi:10.1016/S0140-6736(14)61682-2. PMC 4340604Freely accessible. PMID 25530442 
Md. Mohaiminul Islam, Muhammad Asadul Islam; Radio Frequency Ablation of Liver Tumor-Influence of Large Vessels location and vein wall. Journal of Biomedical Engineering and Medical Imaging, Volume 4, No 6, Dec (2017), pp 16-34

[4] Tungjitkusolmun S, Tyler Staelin S, Haemmerich D, Tsai J-Z, Cao H, Webster J G, Lee F T, Mahvi D M, Vorperian $V$ R. Three-dimensional finite-element analyses for radiofrequency hepatic tumour ablation. IEEE Trans Biomed Eng, vol. 49, No. 1, 2002.

[5] Solbiati L, lerace T, Tonolini M, Osti V, Cova L. Radiofrequency thermal ablation of hepatic metastases. European journal of ultrasound, vol. 13 149-158, 2001.

[6] Welp C, Siebers S, Werner E, Werner J. Invetsigation of the influence of blood flow rate on large vessel cooling in hepatic radiofrequencey ablation. Biomed Tech, vol. 51 337-346, 2006.

[7] Hammerich D, Wright A W, Mahvi D M, Lee Jr F T, Webster J G. Hepatic bipolar radiofrequency ablation creates coagulation zones close to blood vessels: a finite element study. Medical \& biological engineering \& computing, vol. 41, 317-323, 2003.

[8] Kolios M C, Sherar M D Hunt J W. Large blood vessel cooling in heated tissues: a numerical study. Phys. Med. Biol., vol. 40 477-494, 1995.

[9] Gilliams A R, Liver ablation therapy, a review article. The British journal of radiology, vol. 77 713-723, 2004.

[10] Valleylab Cool-tipTM RF ablation system, product information. Available at: http://www.cooltiprf.com/pdf/cool-tip_ss.pdf, accessed: 2007-12-20.

[11] http://www.cool-tiprf.com/index.html surfed on May 2010

[12] Dos Santo I, Haemmerich D, da Silva Pinheiro C, Ferreira da Rocha A, Effect of variable heat transfer coefficient on tissue temperature next to a large vessel during radiofrequency tumor ablation, BioMedical Engineering OnLine, 7 -21, 2008.

[13] Wren J, On medical thermal treatment -modelling, simulationand experiments, Dissertations no. 763, Linköpings University, 2002.

[14] Duck F, Physical properties of tissue, Academic press, London, U.K, 1990.

[15] Berjano E J. Theoretical modelling for radiofrequency ablation: state-of-the-art and challenges for the future. Biomedical engineering online, vol. 5:24, 2006.

[16] Wren J, On medical thermal treatment -modelling, simulationand experiments, Dissertations no. 763, Linköpings University, 2002.

[17] Haemmerich D, Laeseke P F. Thermal tumour abalation: devices, clinical applications and future directions. International journal of hyperthermia, vol. 21:8 755-760, 2005.

[18] Latif M J, Heat Convection, Springer, Heidelberg, Germany, 2006.

[19] http://www.cvphysiology.com/Hemodynamics/H006.htm surfed on November 2010

[20] Miguel A. F., de O Nascimento F. A, da Rocha A. F, dos Santos I, An instrument to measure the convective heat transfer coefficient on large vessels. Conf. Proc. IEEE Eng Med Biol. Soc, 2008. 
[21] P. Keangin, et al., An analysis of heat transfer in liver tissue during microwave ablation using single and double slot antenna, Int. Commun. Heat Mass Transf. (2011), doi:10.1016/j.icheatmasstransfer.2011.03.027

[22] Material property values used in the study obtained from Mordon et al. (2006) and Agalar et al. (2012) .

[23] Berjano EJ. Theoretical modeling for radiofrequencyablation: stateofthe-art and Challenges for the future. Biomed Eng Online. 2006. Apr 18;5:24.

[24] Ottosen $\mathrm{N}$, Petersson $\mathrm{H}$, Introduction to the finite element method, Prentice Hallinternational, UK, 1992.

[25] Montree Chaichanyut and Supan Tungjitkusolmun, Microwave Ablation Using Four-Tine Antenna:

Effects of Blood Flow Velocity, Vessel Location, and Total Displacement on Porous Hepatic Cancer Tissue,2016. 